\title{
Study on the prevention and control measures of China's urban road traffic noise pollution
}

\author{
Qiong Wu, Xiaofeng Zhang ${ }^{*}$, and Guanghua Cao \\ China Academy of Transportation Sciences, Beijing 100029, China
}

\begin{abstract}
Just like the other countries in the world, urban road traffic noise pollution is widespread in China, and with the acceleration of its urbanization process, noise pollution continuously arises. However, China's legislation and governance measures on noise pollution control began in 1989, which is relatively late. Based on the urban road traffic noise pollution status and typical cities' measures in China, and combined with the successful experiences of developed countries, this paper analyzes the causes and puts forward corresponding prevention and control measures from five aspects, such as improving the laws and regulations, focusing on planning and design, thinking highly of Noise Mapping, carrying out special noise reduction projects and strengthening management measures, as a reference for the relevant jurisdictions and scientific researchers.
\end{abstract}

\section{Introduction}

A survey from the World Health Organization (WHO) Regional Office for Europe shows that the relationship between environmental noise and public health is closely relate ${ }^{[1]}$. Noise could have negative impacts on health, including but not limited to causing annoyance, sleep disturbance, negative emotions such as disappointment, anger, unhappiness, anxiety and even depression ${ }^{[2]}$. As the statistics show, 100 million people in the United States are being disturbed by noise. In the United Kingdom, 3/4 residents living in big cities (i.e. London and Liverpool) are seriously being affected by noise, even in Stockholm, Sweden, where it is usually considered as a quiet city, $70 \%$ people are disturbed by noise. Among them, a major part of noise originates from urban traffic. As other countries in the world, China cannot avoid being impacted by terrible urban road traffic noise, and the reasons are complex. This paper will outline the current situation of urban road traffic noise pollution in China and the typical cities' measures, as well as put forward some reasonable suggestions on the noise control in the light of the successful experiences of developed countries. It will also offer some references to control urban road traffic noise pollution for relevant administrative departments and scientific researchers, so as to promote the development of the industry.

\section{The current situation of urban road traffic noise pollution in China}

With the acceleration of its urbanization process, the number of motor vehicles and the consequent noise pollution continuously increase. In 2008 , over $1 / 5$ of the investigated 401 urban roads in China exceeded limits ${ }^{[3]}$. By the end of $2016^{[4]}$, the number of motor vehicles in China reached 290 million, of which 194 million were vehicles and 27.52 million were newly registered. The new registrations and annual growth both reached alltime highs. The noise data collected from 322 cities at the prefecture level and above in $2016^{[5]}$ indicates that, the day-time equivalent continuous A-weighted sound pressure level $\left(L_{\mathrm{eq}}\right)$ of the environmental quality is 54.0 $\mathrm{dB}(\mathrm{A})$, while the urban road traffic $L_{\mathrm{eq}}$ is $66.8 \mathrm{~dB}(\mathrm{~A})$, which accounts for $21.7 \%$ of noise sources. Meanwhile, in the 32 municipalities and provincial capitals of the mainland China, the corresponding environmental quality and the urban road traffic noise in the daytime are 54.5 $\mathrm{dB}(\mathrm{A})$ and $68.5 \mathrm{~dB}$ (A) respectively. The report also shows about $9.6 \%$ of 32 related cities' and $32.4 \%$ of urban roads' traffic noise exceeds $70 \mathrm{~dB}(\mathrm{~A})$. In the same year, 522,300 environmental noise complaints (about $43.9 \%$ of the total environmental complaints) were received by administrative departments at all levels in the country, of which traffic noise accounted for $3.0 \%$. So, it can be concluded that serious road traffic noise pollution is widespread in large, medium and small cities in China, which requires more attentions and effective regulations.

\section{The typical cities' governance measures of urban road traffic noise pollution in China}

In recent years, with the improvement of living standards of the Chinese people, the public pays increasing attention to the prevention and control of urban road traffic noise pollution. And under the efforts, the prevention and control of environmental noise pollution

* Corresponding author: zhangxf422@126.com 
have been continuously promoted throughout the country, and some positive results have been achieved. And it is obvious that the noise governance efforts in first tier cities are far greater than those in other cities in the country.

\subsection{Beijing}

Taking Beijing, the capital of China as an example, the typical characteristics of its urban roads are various overpasses, and its urban road traffic noise control is also an example of all the country. In recent years, the relatively perfect sound noise management system has been established in Beijing and the department coordination mechanism is more and more mature. Under the stewardship, specific and effective countermeasures for various kinds of noise problems have been formulated.

As early as 1999, Beijing took the lead in publishing the Notice on the Use of Sound Insulation Windows in New Buildings on Both Sides of the Road in Beijing (Beijing Huanbao Fu Zi [1999] No.564). It puts forward rigid requirements for sound insulation of exterior windows of new residential buildings, schools, hospitals and other buildings in the $50 \mathrm{~m}$ areas on both sides of the existing and planned roads. In the notice, the criterion of sound insulation windows is no less than $30 \mathrm{~dB}(\mathrm{~A})$ when the roads are expressways and trunk roads, and no less than $25 \mathrm{~dB}(\mathrm{~A})$ when the roads are sub-trunk roads and branch roads. Then, in Beijing Huan Fa [2007] No.141 document, it is required that when selling houses, the sound insulation of buildings must be clearly marked in the sales contracts of houses, so that the buyers would know it very well ${ }^{[5]}$. Beginning in 2008, Beijing has invested 20 million yuan in two phases to organize and construct the largest automatic noise monitoring network in China, with 108 automatic monitoring stations and 24hour dynamic monitoring of acoustic function areas and road traffic noise. The Beijing EPA collects the city's automatic monitoring network data by setting up a central control system to analyze the detected data to form relevant information materials for the daily management of relevant departments ${ }^{[5]}$. At the same time, there has basically established a joint management mechanism composed of various departments in Beijing and the management mode has achieved good results. The environmental protection department shall have unified supervision and management, while the traffic department shall be responsible for the coordination and coordination of traffic noise supervision. In the concrete governance measures, the requirements of Beijing Huan Fa [2010] No.7 document and EIA document must be strictly implemented, for example, the sound barriers, sound insulation windows and other measures should be adopted with new expressways and other projects in accordance with the EIA approvals. According to public suggestions or opinions, the Beijing municipal government has installed noise barriers or carried out sound barrier reconstruction projects in many main roads. Meanwhile, the relevant management regulations have been set up, such as no ring areas, speed limit zones, large truck restricted zones and so on. Under such measures, although the number of vehicles in Beijing is increasing year by year, the traffic noise pollution has remained stable ${ }^{[5]}$.

\subsection{Shanghai}

The urban roads in Shanghai, a financial center of China, are characterized by various viaducts. By the end of 2017 , the total length of Shanghai viaducts is over $350 \mathrm{~km}$ and the typical measures of noise control are noise barriers. Since 2005, all kinds of sound barriers have been installed along with the construction of viaducts in densely populated areas, and the noise reduction effect is obvious. Taking the project of Shanghai Central Ring Line as an example, the overall effect is more than 6 $\mathrm{dB}(\mathrm{A})$, which conforms to the goal designed. Under the protection, the day-time $L_{\mathrm{eq}}$ values of most noise sensitive targets reach the standards. Although those of night-time are still beyond the standards, the sound environment qualities have been significantly improved ${ }^{[6]}$. In addition, by now, Shanghai municipal government has invested plenty of money in building 6 fully-enclosed sound barriers, and the effects are greatly improved.

\section{Suggestions for prevention and control measures}

Through previous analysis ${ }^{[7]}$, influenced by policies and regulations, planning layout, site conditions and other aspects, there are some problems in the control of urban traffic noise pollution in China, such as unclear responsibility subjects, neglect of noise control at planning stage, poor pertinence and feasibility of the measures proposed by EIA, which make it very difficult to control the traffic noise. In view of China's current National Conditions, such corresponding prevention and control measures should be taken into consideration, for example, improving the laws and regulations, focusing on planning and design, thinking highly of Noise Mapping, carrying out special noise reduction projects as well as strengthening management measures.

\subsection{Improving the laws and regulations}

China's legislation on noise pollution control began in $1989^{[8]}$, which is relatively late compared with that in Europe and other developed countries since the 1970s. Among the laws and regulations in mainland China, the most important law related to acoustic environmental protection is Law of the People's Republic of China on Prevention and Control of Pollution for Environmental Noise, promulgated in 1996, which plays a certain role in guiding the control of traffic noise pollution, but it has certain limitations. In view of the fact that the law is currently in the revision period, some suggestions will be discussed below.

First of all, environmental rights in legislation requires more attention. German emphasis on human environmental rights in the legislation should be referenced, such as classifying children's noises under the 
age of 6 as "natural sounds"[9], delimiting all types of speed limit areas for cities ${ }^{[10]}$ and so on. In Germany, they usually set up residential areas where children play regularly as "traffic calming zone" to ensure that motor vehicles lose priority ${ }^{[10]}$, and strict speed restrictions in densely populated areas are set. In the management of urban traffic, German administrators have paid more and more attention to the quiet environment of the neighbourhoods now rather than the smooth flow in the past.

Secondly, according to the existing laws, the construction sequence of roads and noise sensitive targets should be clarified, and related responsibility and the sources of measure funding should be figured out clearly. Then the communication and cooperation between the National Development and Reform Commission, Planning Committee and Environmental Protection Agency should be strengthened. For example, the Hong Kong Environmental Protection Department (EPD) is required to cooperate with the Land Administration Department (LAD) based on the relevant laws and regulations ${ }^{[11,12]}$. The LAD must list the scope of the EPD's authority in the land approvals, following which the land developers have the responsibility to prevent and control the traffic noise with the EPD.

The last but not the least, the sources of vehicle noise should be reduced. For example, the technical means still need to be adopted to reduce the new motor vehicles' noise, so as to ensure the feasibility of legislating to require enterprises to produce "quiet vehicles". In addition, the Chinese needs to better control in scrapping vehicles which do not meet the noise standards. With the aging of vehicle components, single motor vehicle traffic noise often exceeds standards, and the annual vehicle inspection in China does not include vehicle noise monitoring as Germany, which makes the responsibility of traffic noise pollution control very vague and the regulation very difficult.

\subsection{Focusing on planning and design}

Studies show that the function layout, land use attributes, urban road network, red line distance and building layout of urban planning will affect the degree of urban traffic noise pollution ${ }^{[7]}$. The relevant laws and regulations on urban planning and design are the Law of the People's Republic of China for Urban and Rural Planning, etc., which are closely related to urban development, land use right and so on. The urban planning system stipulated in the law is divided into four levels: General Planning, District Planning, Regulatory Detailed Planning and Construction Detailed Planning. But the implementation of the country's overall planning system pays no adequate attention to the traffic noise, and it is lack of effective participation of environmental protection departments, directly resulting in the country's heavy urban road traffic noise pollution as well as the prevention and control is mostly confined to the micro level or terminal control. Therefore, if more attention is paid to the prevention of urban road traffic noise at the level of General Planning and Regulatory Detailed Planning, the headache of regional noise can be soothed effectively.

\subsection{Thinking highly of Noise Mapping}

As a tool widely used to estimate the noise effect on people and improve the future urban development projects, Strategic Noise Mapping was first applied in urban planning used in EU according to Directive 2002/49/EC-the Environmental Noise Directive (END) ${ }^{[13]}$. The Directive introduces the notion of "acoustical planning" which has direct relevance to the development of action plans for noise. "Acoustical planning" refers to "controlling future noise by planned measures, such as land-use planning, systems engineering for traffic, traffic planning, abatement by sound-insulation measures and noise control of sources"[13]. By virtue of including the word "planning", the END points directly towards the role that can be played by national planning systems as a means of mitigating environmental noise in the future. A further element of this strand of the Directive relates to public consultation. And in December 2003 the European Commission's Working Group on the Assessment of Exposure to Noise (WG-AEN) produced the first version of a position paper entitled: good practice guide for strategic noise mapping and the production of associated data on noise exposure (the Guide $)^{[14]}$.

And after years of development, the application of Strategic Noise Mapping has been well established in EU, but it is still at its initial stage in China. Since the first noise map was published in 2002, a three-dimensional version has been released in 2010 in Hong Kong. It plays an important role in supporting the formulation of noise control policies and plans, the analysis of noise suitability of construction projects and the enhancement of public participation. According to the statistics, the number of people affected by excessive traffic noise in Hong Kong decreased from 1.14 million in $2002(17.3 \%)$ to 960,000 $(13.6 \%)$ in $2010^{[15]}$. According to Huanfa [2010] No.144 document, pilot work has been carried out in some key cities in China to draw noise maps to guide the prevention and control of local noise pollution. But, until 2008 in the Mainland the first noise map was reported, covering about 12 square kilometres of Shenzhen ${ }^{[16]}$. So far, Noise mapping has been developed in at least 14 cities in China, such as Beijing, Shanghai, Shenzhen, Hangzhou etc., and some achievements have been made ${ }^{[15]}$. However, the application of noise mapping in mainland cities is mainly limited to the cases of local EPA for individual noise incidents. Normal application has not been carried out and services have not been provided to the public and other departments, let alone the application of Strategic Noise Mapping. It's no doubt that there's still a long way to go before it can be applied to guide regional noise control at the level of urban planning like EU. All in all, as an advanced tool, the noise mapping should be used to control urban road traffic noise pollution throughout the whole stage of planning, so as to form the combination of macroscopic and microcosmic angle, of local and global control strategies, and of adopting active and passive regulation 
measures. These require the government administrators and building developers to coordinate with each other, and to control the urban road traffic noise pollution in a comprehensive way.

\subsection{Carrying out special noise reduction projects}

Special noise reduction projects should be funded by the Chinese government in such cases that the laws are not clearly defined or the responsibility for noise reduction is unclear or the pollution is too serious. For example, housing energy saving reform, city renovation should be combined with the replacement of sound insulation windows, and road maintenance should be combined with low noise pavement engineering and so on. In addition, the Chinese government administrators could get some inspiration from the German "green wave" noise reduction project ${ }^{[17]}$. That is to say, when a car runs at a constant speed (i.e. about $60 \mathrm{~km} / \mathrm{h}$ ) on the road, the traffic lights will turn green all the way. So it can not only ensure the smooth running, but also reduce fuel consumption and corresponding air and noise pollutants.

\subsection{Strengthening management measures}

In addition, management measures such as no tooting zones, speed limit regulation, traffic calming zones, signal control and traffic guidance should be strengthened. At present, due to the need of urban construction in China, besides buses, there are more large vehicles and transport vehicles in the night-time, resulting in heavy traffic noise pollution, which influence the sound environment of the areas on both sides greatly. So how to ensure the normal construction of the city and the acoustic environmental quality in the night-time is a challenge facing the Chinese government administrators.

\section{Conclusion}

As one of the largest countries in population and the number of cars, China is certainly no exception of the serious urban road traffic noise. Based on the real condition of China, consideration should be given to all aspects such as noise related laws and regulations, city and road planning and layout, technical specifications, end-treatment measures and so on. In short, the most important idea of urban road traffic noise control is "prevention is better than treatment".

This work was supported by Central Public-interest Scientific Institution Basal Research Fund (No. 20170618), which should be gratefully acknowledged.

\section{References}

1. L. Fritschi, L. Brown, R. Kim, D. Schwela, S. Kephalopoulos, Burden of Disease from Environmental Noise-Quantification of Healthy Life Years Lost in Europe (Copenhagen: WHO Regional Office for Europe) (2011)
2. E. Murphy, E.A. King, Environ. Int. 36, 290-298 (2010)

3. B.G. Li, S. Tao, Environ. Protect. Trans. 22, 5-9 (2001) (in Chinese)

4. G.W. Liu, Environ. Dev. 29, 65-66 (2017) (in Chinese)

5. 2017 China Environmental Noise Pollution Prevention and Control Annual Report (Beijing: Ministry of Environmental Protection of the People's Republic of China Report) (in Chinese)

6. X.F. Qiu, X.B. Dai, J.P. He, J. Shanghai Ship Shipping Res. Inst. 40, 60-63+70 (2017) (in Chinese)

7. X.D. Lu, Study on Road Traffic Noise Control from the Angle of Urban Planning (Dalian: Dalian University of Technology Thesis) (2013) (in Chinese)

8. Chinese State Council 1989 Regulations on Prevention and Control of Environmental Noise Pollution in People's Republic of China (Beijing) (in Chinese)

9. Z.L. Chen, World Environ. 76-78 (2015) (in Chinese)

10. K.P. Li, X.C. Yu, Y.L. Chen, Urban Trans. China 16, 96-102 (2018) (in Chinese)

11. S.Y. Liu, D.X. Song Housing Sci. 39-42 (2002) (in Chinese)

12. T.T.K. Ho, C. Mak, H.F. Chan, Tech. Acoust. 28, 778-786 (2009) (in Chinese)

13. European Union 2002 Directive 2002/49/EC Relating to the Assessment and Management of Environmental Noise ( Official Journal of the European Communities).

14. [Hinton J and Bloomfield A Acoust. Bull. 29, 18-21 (2004)

15. X.H. Hu, The 4th Int. Conf. on management Technology for Environmental noise and vibration control (Beijing: Environmental engineering assessment center of Ministry of environmental protection) (2018) (in Chinese)

16. T. Yu, Environ. Sci. Manage. 39, 129-133 (2014) (in Chinese)

17. K.L. Chen, Environ. Herald. 45-46 (2001) (in Chinese) 